\title{
RECOMBINATION IN ESCHERICHIA COLI
}

\author{
III. MAPPING BY THE GRADIENT OF TRANSMISSION* \\ I. G. DE HAAN, W. P. M. HOEKSTRA, C. VERHOEF AND H. S. FELIX \\ Laboratory for Microbiology, State University, Utrecht (The Netherlands) \\ (Received September Ist, I969)
}

SUMMARY

Mapping of markers on the Escherichia coli chromosome by the gradient of transmission is presented. The method appeared to be useful and accurate if chromosome withdrawal is prevented and if the viability of the zygotes is assured.

The guaC was mapped by this method in the 89-90 min region of the chromosome map of TAYLOR AND TROTTER.

\section{INTRODUCTION}

The first step in bacterial conjugation is the random collision of cells of opposite mating type and the formation of a conjugation bridge between them ${ }^{5}$. This step is followed by the transfer of genetic material from donor to recipient cell. In $\mathrm{Hfr} \times \mathrm{F}^{-}$ crosses, it starts from the same point in all cells of a given Hfr type and proceeds in a pre-determined sequence, ${ }^{\boldsymbol{6}}{ }^{16}$. The transfer of the whole chromosome is completed ${ }^{14}$ in about go min.

Spontaneous interruption of conjugation by breakage of the conjugation bridge usually occurs before the entire donor chromosome has been transferred. Thus zygotes generally receive only a fragment of the donor chromosome, the size of the fragment differing from zygote to zygote. The further a given marker is from the origin, the lower is the probability that it is transferred to the zygotes (gradient of transfer). The transfer process has been studied experimentally by stopping conjugation at intervals by shaking to break up the conjugation bridge ${ }^{16}$ or by killing ${ }^{\mathbf{6}, 13}$ the donor with phage $\mathrm{T} 6$.

It was found that each genetic marker in a given $\mathrm{Hfr} \times \mathrm{F}^{-}$cross begins to enter the zygotes at a different and specific time after the beginning of mating. Thereafter the number of zygotes, and consequently the number of recombinants which inherit the donor marker, rises until a plateau level is reached. The time interval between the curves for various donor markers can be translated into a time scale which is a function of the physical distance between these markers.

\footnotetext{
* For parts I and II of this series see refs. I5 and 2.
} 
The transfer time of a given marker is defined as the tince at which the first recombinants are found, $i . c$ the intersection point of the curve with the time axis. The shape of the transfer curve is a very complex one and is dependent on a number of factors, such as contact formation and transfer delay. The intersection point with the time axis is therefore difficult to determine, although good results have been obtained with this method.

The spontaneous breakage of the bridge during the transfer process causes an exponential gradient of transfer ${ }^{16}$. As any donor marker has the same probability of being incorporated into a recombinant once it has entered the zygote ${ }^{8}$, there is a gradient of transmission for the various Hfr markers. Mapping by the gradient of transmission is in principle possible as has been suggested by $\mathrm{HAYLS}^{7}$ and recently by WoOD ${ }^{17}$. As far as we know, however, this method has never been used. In this paper a method for mapping by the gradient of transmission is presented.

\section{MATERIALS AND METHODS}

\section{Bacterial strains}

Bacterial strains employed are listed in Table I. All donor strains are Strs; all recipient strains are $\operatorname{Str}^{r}$.

TABLE I

BACTERIAL STRAINS

\begin{tabular}{|c|c|c|c|c|c|c|c|c|c|c|c|}
\hline \multirow[t]{2}{*}{ Strain } & \multicolumn{11}{|c|}{ Auxotrophic markers } \\
\hline & his & $i l v$ & leu & met & pro & $p u r$ & $p y r$ & thi & thr & $t r p$ & $t y r$ \\
\hline ooog Hfr H (ref. 5) & + & + & $\dot{\dagger}$ & + & -1. & +- & + & & + & $\ldots$ & + \\
\hline $0020 \mathrm{Hfr} \mathrm{R}_{4}$ (ref. I2) & + & $\therefore$ & + & + & -1 & t & -+ & $\cdot+$ & 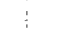 & $\dot{-1}$ & $i$ \\
\hline $002 \mathrm{I} \mathrm{Hfr} \mathrm{R}_{4}$ & $-\cdots$ & + & $-t$ & $\ldots$ & +1 & $p u r H$ & pyrA & $\ldots$ & : & + & . \\
\hline $\mathrm{Hfr} \mathrm{KL} I 6^{\mathrm{b}}$ & + & + & it & : & $\cdots$ & + & $i$ & $\ldots .$. & + & 1 & 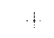 \\
\hline $\mathrm{OI}_{72} \mathrm{~F}-\mathrm{KI} 2$ & - & + & -+ & t & t: & $g u a B$ & $-t$ & & + & $\ldots$ & $\cdots$ \\
\hline $0205 \mathrm{~F}-\mathrm{KI} 2$ & $-i$ & + & $\cdots$ & 1 & pro. 4 & $p u r 4$ & $\vdots$ & : & .. & + & $\cdots$ \\
\hline $0206 \mathrm{~F}-\mathrm{KI} 2$ & + & + & $\ldots$ & 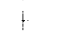 & prots & purs & $\vdots$ & . & & + & $:$ \\
\hline $0207 \mathrm{~F}-\mathrm{KI} 2^{\mathrm{c}}$ & -.. & + & + & $i$ & pro. & $\begin{array}{l}\text { purH } \\
\text { guaC }\end{array}$ & 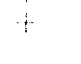 & & 1 & $\cdots$ & \\
\hline $\mathrm{O} 2 \mathrm{I} 2 \mathrm{~F}-\mathrm{KI} 2^{\mathrm{c}}$ & - & --- & $\therefore$ & + & pro. A & $\begin{array}{l}\text { purH } \\
\text { guaC }\end{array}$ & $-i$ & $\cdots$ & - & - & $\cdots$ \\
\hline
\end{tabular}

a Cultures of these strains are present in the phabagen collection, Laboratory for Microbiology, Utrecht.

b Obtained by the courtesy of Dr. B. L.ow.

c Obtained by the courtesy of Dr. H, J. J. NijkAmp.

\section{Bacterial crosses}

Overnight cultures of donor and acceptor strains in nutrient broth were diluted Io-fold in pre-warmed broth and incubated at $37^{\circ}$ for $90 \mathrm{~min}$ on an inclined turntable (cell density $2 \cdot 10^{8} / \mathrm{ml}$ ). Mating mixtures were obtained by mixing I volume of donor with ro volumes of recipient culture. 5 min after mixing, the nonrotated suspension was diluted rooo-fold in pre-warmed broth, and a suitable transfer period was allowed. During transfer, the mating mixture was generally incubated without shaking, but in some experiments the mixture was gently shaken. Mating was interrupted by vigorously shaking on a microid flask shaker. The zygotes were incubated 
in broth for 75 min before plating. Donor cells were killed by streptomycin in the selection plates or by addition of excess phage T6 to the blended suspension.

Recombinants were selected on appropriate selection plates. The number of recombinants was determined by counting 5 plates, each with a suitable number of recombinants $(30-300)$.

The necessary growth factors were added at the following concentrations: adenine $20 \mu \mathrm{g} / \mathrm{ml}$, guanine $20 \mu \mathrm{g} / \mathrm{ml}, d l$-histidine $20 \mu \mathrm{g} / \mathrm{ml}, d l$-isoleucine $20 \mu \mathrm{g} / \mathrm{ml}$, $d l$-leucine $40 \mu \mathrm{g} / \mathrm{ml}, d l$-methionine $20 \mu \mathrm{g} / \mathrm{ml}, d l$-proline $60 \mu \mathrm{g} / \mathrm{ml}$, thiamine $10 \mu \mathrm{g} / \mathrm{ml}$, $d l$-threonine roo $/ \mathrm{g} / \mathrm{ml}$, dl-tyrosine $20 \mu \mathrm{g} / \mathrm{ml}$, dl-tryptophane $20 \mu \mathrm{g} / \mathrm{ml}$, dl-valine $20 \mu \mathrm{g} / \mathrm{ml}$.

Streptomycin was added at a concentration of $100 \mu \mathrm{g} / \mathrm{ml}$.

\section{EXPERIMENTAL PLAN AND RESULTS}

Let us consider a hypothetical cross in which each Hfr cell transfers its chromosome in the order: origin - A-B-C - . . T. Hfr and $\mathrm{F}^{-}$cells are mixed and, after a short period necessary for contact formation, the mixture is diluted to stop the formation of new contacts. Transfer begins after the formation of contacts although the initiation of transfer in the population is not synchronized ${ }^{1}$. The number of mating pairs decreases with time due to the spontaneous breakage of the conjugation bridge, and in some systems the breakage is accompanied by withdrawal of the transferred donor fragment from a fraction of the mating acceptor cells. We will assume that chromosome withdrawal is absent and that each mating pair has the same constant probability $(k)$ per unit time for spontaneous separation. The probability that the two cells of a mating pair are not separated in a time interval $t$ is then: $\exp (-k t)$.

The rate of transfer is constant in all mating pairs, which means that the interval in transfer time between two markers is constant in all mating pairs. Based upon these considerations we may state that after the completion of transfer of a given marker $\mathrm{T}$, transferred $t$ min after a more proximal marker $\mathrm{A}$, the number of $\mathrm{F}^{-}$- cells which contain the $T$ marker is:

$$
F(\mathrm{~T})=F(\mathrm{~A}) \exp (-k t)
$$

where $F(\mathrm{~A})$ represents the number of $\mathrm{F}^{-}$cells which contain the A marker.

The number of recombinants $(R)$ which may be recovered from the (blended) suspension depends on the number of $\mathrm{F}$ - cells which contain the marker and on the probability that the transferred marker is incorporated in the acceptor chromosome. As stated before, the incorporation probability is assumed to be equal for all markers. Thus

$$
R(\mathrm{~T})=R(\mathrm{~A}) \exp (-k t)
$$

or

$$
\log _{10} R(\mathrm{~T})=\log _{10} R(\mathrm{~A})-0.43 k t
$$

This equation predicts a straight line when the $\log _{10}$ of the number of $\mathrm{T}^{+}, \mathrm{C}^{+}, \mathrm{B}^{+}$ and $\mathrm{A}^{+}$recombinants is plotted against the transfer intervals between the involved marker and the marker $\mathrm{A}$. 


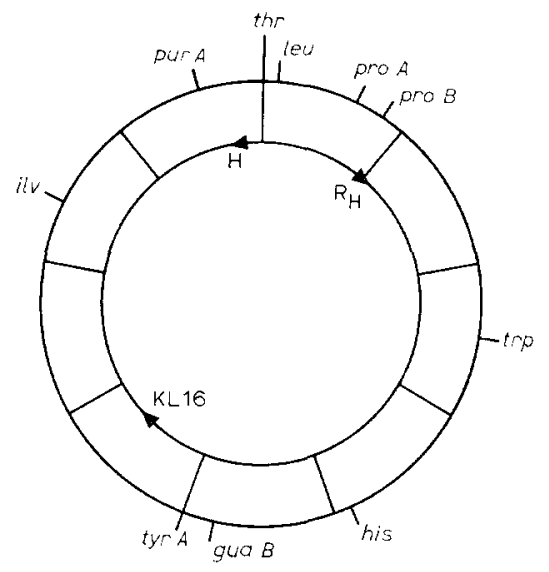

Fig. I. Position of relevant markers and origins of the Hfr strains.
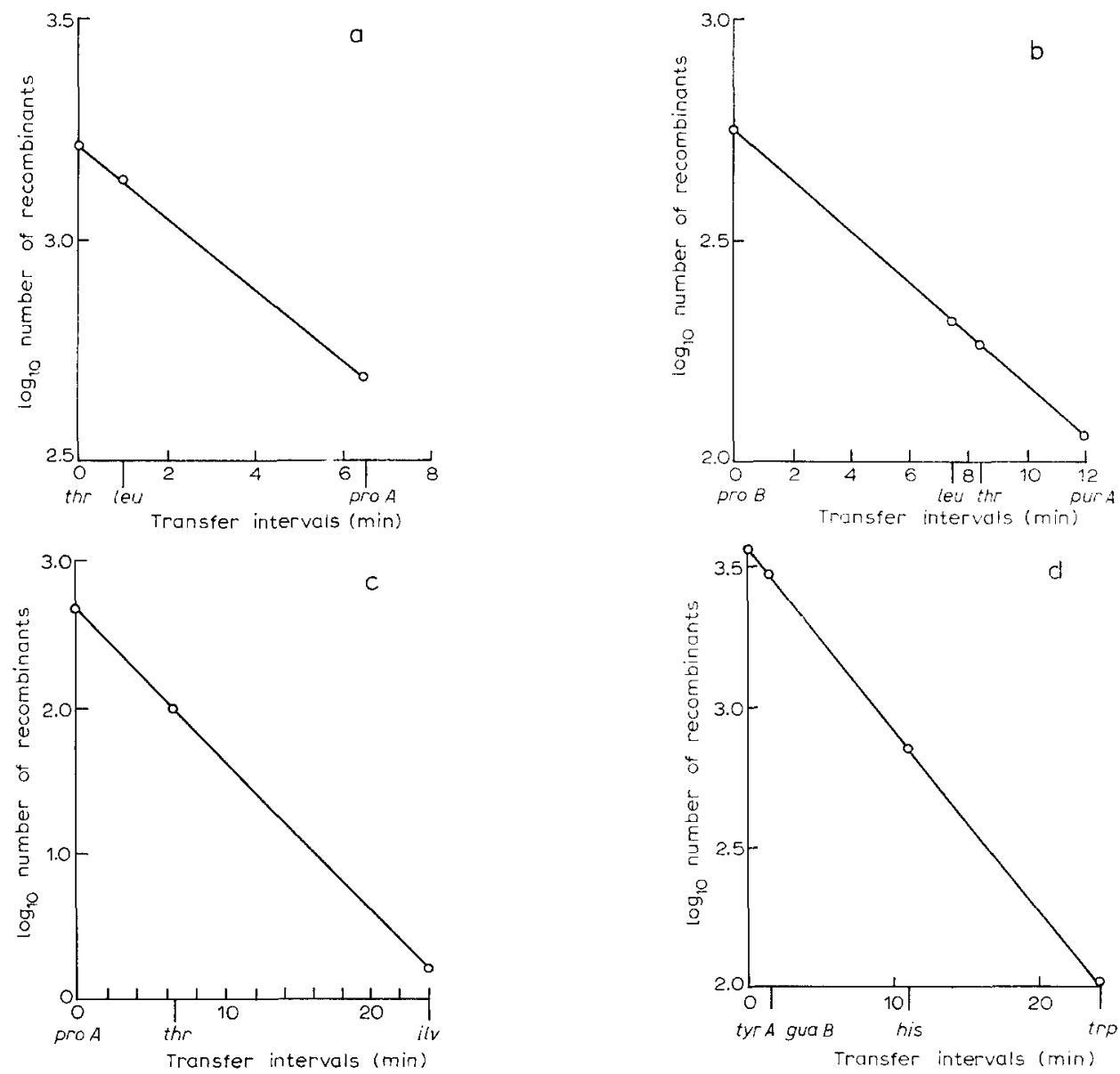

Fig. 2. Results of bacterial crosses. (a) $\mathrm{Hfr} \mathrm{H} \times 0205$; (b) $\mathrm{Hfr} \mathrm{R}_{4} \times 0206$; (c) $\mathrm{H} f \mathrm{r} \mathrm{R}_{4} \times 02 \mathrm{r}_{2}$; (d) Hfr KLI $6 \times$ or 72 . Transfer intervals for the pur $A \ldots \ldots$ proB region are derived from VERHOEF AND DE HAAN ${ }^{15}$; the other intervals are derived from the TAYLOR AND TROTTER ${ }^{14}$ map. 
The validity of eqn. (2) was tested in a series of crosses (see Fig. I for marker position and $\mathrm{Hfr}$ types). In the crosses with Hfr $\mathrm{H}$ or Hfr $\mathrm{KL}$ I 6 as donor, the mating mixture was not shaken and the donor cells were killed by streptomycin. In the two crosses with $\mathrm{Hfr} \mathrm{R}_{4}$ as donor, the mating mixtures were gently shaken in a shaking machine (120 strokes per min) to minimize the interference by chromosome withdrawal which is observed in crosses with this Hfr. Unshaken crosses with Hfr $\mathrm{R}_{4}$ as donor always gave slightly bent curves. The results of the crosses are presented in Fig. 2. It may be seen from Fig. 2 that a straight line was obtained from all crosses, proving that eqn. 2 is valid for the first 15 -min transfer by $\mathrm{Hfr} \mathrm{H}$ and for the first 30-min transfer by Hfr R4 or Hfr KLi6.

\section{CALCULATION OF TRANSFER INTERVALS}

Relation 2 may be used for the mapping of a marker with unknown transfer time if two or more markers with known transfer intervals are available. The first step is the calculation by the method of least squares of the parameters of the regression line:

$$
\left(Y_{x}-\bar{Y}\right)=b(X-\bar{X})
$$

where: $Y_{x}$ is the logarithm of the number of recombinants of a marker transferred $X$ min after the first reference marker. $\bar{Y}$ is the mean of the logarithms of the number of recombinants inheriting the reference markers. $b$ is the slope of the curve. $\bar{X}$ is the mean of the transfer intervals of the reference markers.

The Ioo $(\mathrm{I}-\alpha) \%$ confidence limits for the transfer time $X$ of the unknown marker is then calculated from the mean of the logarithms of the number of recombinants $\left(\bar{Y}_{x}\right)$ with the aid of eqn. (4) (see Dixon AND MAsseY ${ }^{3}$ ).

$$
\bar{Y}_{x}=\bar{Y}+b(X-\bar{X}) \pm t_{\frac{1}{2} \alpha} S_{y x}\left[\frac{\mathrm{I}}{n}+\frac{\mathrm{I}}{m}+\frac{(X-\bar{X})^{2}}{(n-\mathrm{I}) S_{x}^{2}}\right]^{\frac{1}{2}}
$$

or from its equivalent form:

$$
\left[\bar{Y}_{x}-\bar{Y}-b(X-\bar{X})^{2}\right]^{2}=t_{\frac{1}{2} \alpha} S_{y x}^{2}\left[\frac{\mathrm{I}}{n}+\frac{\mathrm{I}}{m}+\frac{(X-\bar{X})^{2}}{(n-\mathrm{I}) S_{x}^{2}}\right]
$$

where $n$ is the total number of observations from which the regression coefficients are calculated, $m$ is the number of observations on which $\bar{Y}_{x}$ is based, and $t_{1} x$ represents the percentile of the $t$-distribution for $(n-2)$ degrees of freedom (see ref. 3 , Table A-5).

The results of the $\mathrm{Hfr} \mathrm{R}_{4} \times \mathrm{F}^{-}$purA thr leu proB cross (Fig. $2 \mathrm{~b}$ ) will serve as an example for the calculation of the transfer interval proB-thr. The data of this cross are given in Table II, and the regression line based on the observed numbers of proB $B^{+}, l e u^{+}$and $p u r A^{+}$recombinants is:

$$
\left(Y_{x}-2.38\right)=-0.0576(X-6.5)
$$

The $95 \%$ confidence limits for the transfer interval proB-thr are obtained by straightforward solution of : 


$$
\left[\begin{array}{lll}
-0.13 & 0.0576(X & 0.5)
\end{array}\right] 2 \cdots 0.0046\left[\begin{array}{cc}
4 & (X-0.5)^{2} \\
15 & 307.5
\end{array}\right]
$$

from which it follows that: $X=8 \mathrm{~min} 43 \mathrm{sec} \pm 37 \mathrm{sec}$. The transfer interval prob thr determined from time of entry experiments and from recombinant analysis is 8 min $30 \mathrm{sec}$.

TABLE II

DATA OF A Hfr $\mathrm{R}_{4} \times 0206$ CROSS

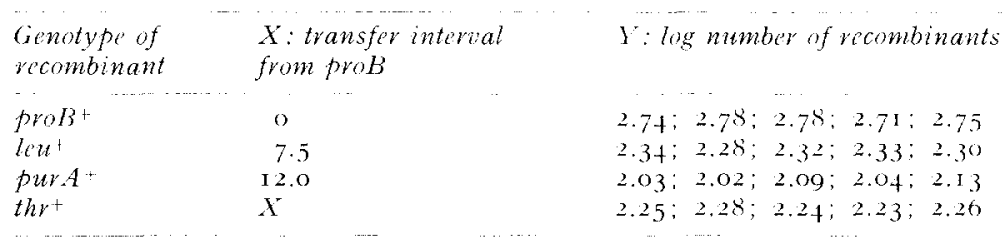

The table gives the data of the experiment diagrammed in liig. 2 b.

For experimental details, see text.

The parameters of the regression line are $x \quad 6.5, \quad \overline{3} \quad-2.38$ and $b-0.0567$.

The guaC marker, tentatively localized by NIJKAMP AND DE HAAN ${ }^{10}$ was also mapped with this method. The $\mathrm{Hfr}_{4}$ as well as the acceptor strain $0207 \mathrm{~K}_{2} \mathrm{~F}^{-}$ contained a purH marker which allows the selection of $g u a C^{+}$recombinants on a medium with guanine as purine source. In the first cross pro $A$ and $t h r$ were used as reference markers. The calculated interval proA-guaC was 7 min 12 sec : 24 sec. In a second cross, the same $\mathrm{Hfr}$ was crossed with an $i l$ derivative of the 0207 acceptor strain. Here $i l v, t h r$ and prod were used as reference markers and the interval pro $A$ $g u a C$ was 6 min $42 \mathrm{sec}+\mathrm{I} 6 \mathrm{sec}$. The mean of the two determinations is 6 min $57 \mathrm{sec}$. The guaC is thus transferred by Hfr $\mathrm{R}_{4}$ about 30 sec later than the thr marker.

\section{DISCUSSION}

In the present study a method for the calculation of intervals in transfer time is presented. The method is based on the exponential gradient of transmission which manifests itself as a consequence of the random breakage of the conjugation bridge. In the example given in this paper, the transfer interval proB-thr was calculated from a cross in which the proB, leu and pur $A$ markers were used as reference markers. The interval proB-thr was calculated as $8 \mathrm{~min} 43 \mathrm{sec}$ which is in good agreement with an interval of $8 \mathrm{~min} 30 \mathrm{sec}$, obtained from transfer curves or calculated from recombinant analysis. The interval was determined with an error of $\pm 7 \%$; the calculation of the confidence limits being based on the assumption that the transfer intervals between the reference markers are accurately known.

The method is more accurate than the time-of-entry method, and its accuracy can be enhanced by increasing the probability of breakage of the bridge (shaking). The easiest method, however, for the determination of the order of closely linked markers is transduction, in spite of the fact that a mapping function based upon transduction frequencies is not available.

A number of experimental conditions are important in mapping by the gradient 
of transmission. A differential viability of certain recombinant classes was observed in some crosses if zygotes were plated immediately after the interruption of transfer. Good results were obtained when the zygotes were incubated for about two generations in broth before plating. This is in agreement with observations that the recovery of recombinants from zygotes is sensitive to a metabolic shift-down ${ }^{1}$ and with the observation that the mathematical analysis of recombination data is useful only if zygotes are incubated in broth before plating.

A second factor is the chromosome withdrawal which is observed in crosses with certain Hfr strains as donors. The effect of withdrawal decreases the number of zygotes which receive a given donor marker and this effect is greater for proximal than for distal markers, due to the limitation of the transfer period. Experimental conditions which prevented withdrawal, such as gently shaking of the mating mixture, again gave an exponential gradient of transmission.

The random breakage of the conjugation bridge predicts an exponential gradient of transfer of donor markers to the zygotes. The number of recombinants which may be obtained from a zygote suspension depends on the number of zygotes which received that particular marker and on its incorporation frequency in the zygotes. The exponential gradient observed in the number of recombinants shows that the incorporation frequencies of the markers in each cross presented in this paper are equal.

The experiment with $\mathrm{Hfr}_{4}$ as donor shows that the incorporation frequency of the pro $B$ marker, which may be regarded as an early marker ( $0.5 \mathrm{~min}$ from the origin), was normal.

More proximal markers than proB, however, may be incorporated with a lower probability. GlansdorfF, as well as PitTARd AND WALker ${ }^{11}$, have shown that certain markers near to the origin are incorporated at a lower frequency than other markers. Experiments of Low ${ }^{9}$ point in the same direction. The low incorporation of early markers would make mapping of these markers by the gradient of transmission impossible.

\section{REFERENCES}

I De HaAn, P. G., and J. D. Gross, Transfer delay and chromosome withdrawal during conju. gation in Escherichia coli, Genet. Res., 3 (I962) $25 \mathrm{I}-272$.

2 De HaAn, P. G., AND C. Verhoef, Genetic recombination in Escherichia coli, II. Calculation of incorporation frequency and relative map distance by recombinant analysis, Mutation Res., 3 (I966) II I-II 7 .

3 Dixon, W. J., And F. J. Massey, Introduction to Statistical Analysis, end ed., McGraw-Hill, New York, 1957, p. I92.

4 Glansdorff, N., Pseudo inversion in the chromosome of Escherichia coli Kr2, Genetics, 55 (I966) $49-6$ I.

5 Hayes, W., The mechanism of genetic recombination in Escherichia coli, Cold Spring Harbor Symp. Quant. Biol., I8 (1953) 75-93.

6 Hayes, W., The kinetics of the mating process in Escherichia coli, J. Gen. Microbiol, I6 (1957) 97-II9.

7 HAYes, W., The Genetics of Bacteria and Their Viruses, Blackwell, Oxford, 1964, p. 584.

8 Jacob, F., And E. L. Wollman, Sexuality and the Genetics of Bacteria, Academic Press, New York, I96I, p. I 52 .

9 Low, B., Low recombination frequency for markers very near to the origin in conjugation in Escherichia coli, Genet. Res., 2 (1965) 406-413.

io NiJkamp, H. J. J., ANd P. G. DE HaAn, Genetic and biochemical studies of the guanosine 5 'monophosphate pathway in Escherichia coli, Biochim. Biophys. Acta, I45 (I967) 3I-40. 


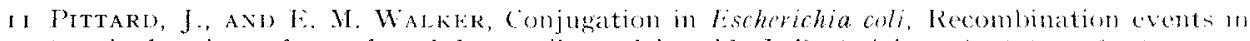
terminal regions of transferred desoxyribonucleic acid, J. Bacteriol., 9+ (106-) it556-I6t:3.

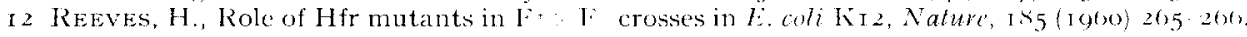

I3 SKAAR, P. D., AND A. (iAREN, The orientation and extent of gene transfer in Escherichia chl, Proc. Natl. Acad. Sci. (U.S.), 42 (1956) 6rg-624.

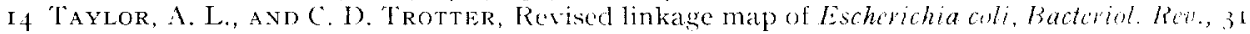
(I967) $332-353$.

I 5 VERHOFF, C., AND P. (x. DE HAAX, Genetic recombination in Escherichia coli, 1. Relation between linkage of unselected markers and map distance, Mutation Res., 3 (1966) IoI-I Io.

I6 Wollman, E. L., AND F. JACOB, Sur les processus de conjugaison et de recombinaison chez Escherichia coli, V. Le mécanisme du transfert de matériel génétique, Ann. Inst. Pastetur. 95 (1958) $64 \mathrm{I}-666$.

I7 Wood, Тн. H., Effects of temperature, agitation, and donor strain on chromosome transfer in Escherichia coli $\mathrm{KI} 2$, J. Bacteriol., $9^{6}(1968) 2077^{-208} 4$.

Mutation Res., 8 (1969) 505-512 